\title{
Enhancing Toughness and Impact Strength of Epoxy Resins by Using Hyperbranched Polymers
}

\author{
Hangyu Park and Youngson Choe \\ Department of Polymer Science and Chemical Engineering, Pusan National University, Geumjeong-Ku, Jangjeong-Dong, \\ Busan 609-735, Republic of Korea \\ Correspondence should be addressed to Youngson Choe; choe@pusan.ac.kr
}

Received 31 August 2021; Revised 2 November 2021; Accepted 20 November 2021; Published 11 December 2021

Academic Editor: Yulin Deng

Copyright (c) 2021 Hangyu Park and Youngson Choe. This is an open access article distributed under the Creative Commons Attribution License, which permits unrestricted use, distribution, and reproduction in any medium, provided the original work is properly cited.

\begin{abstract}
Toughened epoxy has been widely used in industrial areas such as automotive and electronics. In this study, nanosized hyperbranched polymers (HBPs) as a flexibilizer are synthesized and embedded into epoxy resin to enhance the toughness and flexibility. Two different HBPs, hyperbranched poly(methylacrylate-diethanolamine) (poly(MA-DEA)) and poly(methylacrylate- ethanolamine) (poly(MA-EA)), were prepared and blended with both epoxy and polyetheramine, a curing agent. The molecular size of HBPs was estimated to be $6 \sim 14 \mathrm{~nm}$ in diameter. The molecular weight of HBPs ranges from $1500(1.5 \mathrm{~K})$ to $7000(7.0 \mathrm{~K}) \mathrm{g} / \mathrm{mol}$. In cured epoxy/HBP blends, no phase separations are occurred, indicating that HBPs possess sufficient miscibility with epoxy. The tensile toughness of the blends increased with changing the molecular weight of HBPs without sacrificing tensile strengths. The impact strength of the blends increases stiffly until the loading \% of HBPs in the blends reaches $10 \mathrm{wt} \%$. In addition, the experimental studies showed that impact resistance also increased with an increase in molecular weight of HBPs. The obtained impact resistance of the epoxy/HBP blends with $10 \mathrm{wt} \%$ was $270 \%$ more effective compared to that of cured neat epoxy.
\end{abstract}

\section{Introduction}

Toughened epoxy resins exhibit excellent mechanical properties and are widely used in high performance composites and structural adhesives [1-4]. Many of the research works have been conducted to overcome the low impact resistance and low toughness properties of epoxy resins. For several decades, significant signs of progress have been developed to enhance both adhesion strength and impact resistance by incorporating micrometer sized liquid rubbers [5], coreshell rubber (CSR) particles [6], and thermoplastic particles [7-14]. Block copolymer particles as tougheners have also attracted considerable attention $[15,16]$. These block copolymers tend to be self-assembled to form certain nanostructures in the epoxy matrix during the cure process. These self-assembled nanostructures can improve the fracture toughness without affecting the $\mathrm{Tg}$ (glass transition temperature) and tensile strength of cured epoxy resins. Most of the toughening materials except CSR particles are less effective at low temperatures. In this study, nanoscale hyperbranched polymers (HBPs) are synthesized as tougheners and incorporated into epoxy resin to improve the toughness and flexibility of epoxy resins.

Hyperbranched polymers are densely branched macromolecules with a three-dimensional globular structure. HBPs are attracting attention as a polymer that has low viscosity, abundant functional groups, small chain entanglement, large free volume, high solubility, and easy synthesis. Because of these features, HBPs can be used for various applications in epoxy systems [17], such as coating materials $[18,19]$ and modifiers [20, 21]. More interestingly, in several reports, performances in toughness have been found in epoxy resins incorporated with hyperbranched polymers as a toughener [22]. HBPs with various functional groups such as epoxide [20], carboxylic acid [23], hydroxyl [24], and amine can increase the toughness of epoxy resins [25].

HBPs are highly effective polymer modifiers for thermosetting materials including epoxy resins, due to (1) their net- 
<smiles>C=CC(=O)OC</smiles>

Methylacrylate (MA) $\mathrm{AB}$<smiles>OCCNCCO</smiles>

Diethanolamine (DEOA) $\mathrm{CD}_{2}$

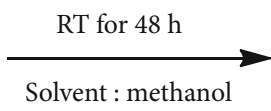

Solvent : methano<smiles>COC(=O)CCN(CO)CO</smiles>

Intermediate $\mathrm{AD}_{2}$

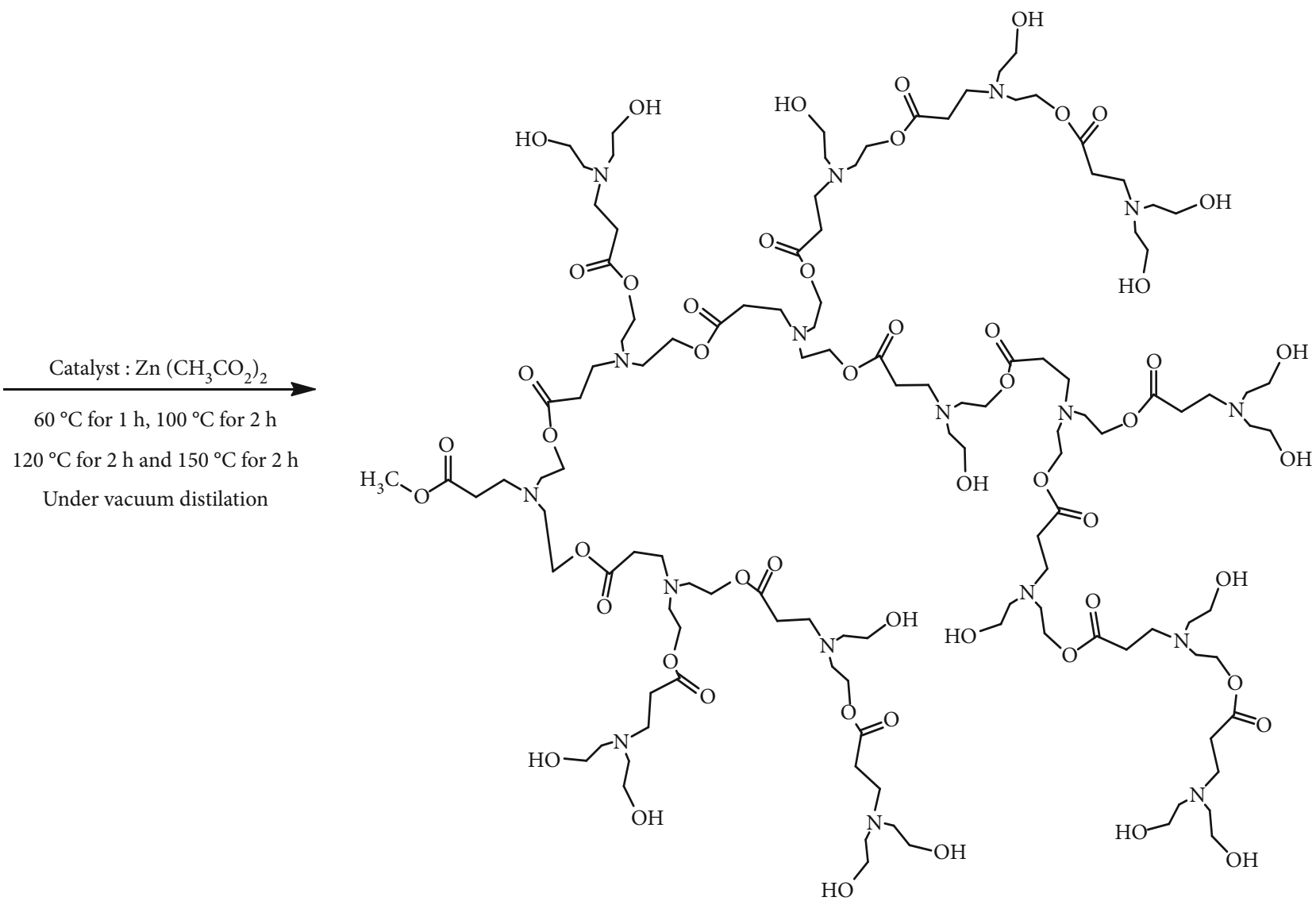

Scheme 1: Synthetic route of hyperbranched poly(MA-DEA) (HBP1).

work with a spherical structure which can reduce the shrinkage of epoxy resins due to the extensible branching chains of HBPs; (2) their high density and versatile functional end groups such as hydroxyl, amine, epoxide, anhydride, carboxyl, and isocyanate groups, which can significantly improve the compatibility between HBPs and epoxy matrices; and (3) large free volumes in their networks, which can significantly improve the toughness of epoxy resins when HBPs are used as modifiers [26].

In this work, we investigated the effect of nanosized HBP particles, possessing hydroxyl or carbonyl end groups, on the toughness and flexibility of epoxy resins. Hydroxyl end groups are reported to be involved in crosslinking reactions of epoxy resins.

\section{Materials and Methods}

2.1. Materials. Diglycidyl ether bisphenol-A (DGEBA) (EEW: 184-190, Kukdo Chemical) as an epoxy resin and polyetheramine (AHEW $=115 \mathrm{~g} /$ equiv, Huntsman D-400) as a curing agent are used as obtained. Hyperbranched poly methylacrylate-diethanolamine (poly(MA-DEOA)) and poly methylacrylate-ethanolamine(poly(MA-EA)) were synthesized as toughening agent as well as flexibilizer.

2.2. Synthesis of Hyperbranched Poly(MA-DEA). Two step reactions were carried out to synthesize hyperbranched poly(MA-DEA); in the first step, $0.5 \mathrm{~mol}$ of methylacrylate (MA) and diethanolamine (DEA) was added into methanol $(100 \mathrm{~mL})$ and stirred for $48 \mathrm{~h}$, and in the second step, $0.25 \mathrm{~g}$ of $\mathrm{Zn}\left(\mathrm{CH}_{3} \mathrm{CO}_{2}\right)_{2}$ was added into the solution, and the reaction was carried out at $60^{\circ} \mathrm{C}$ for $1 \mathrm{~h}, 100^{\circ} \mathrm{C}$ for $2 \mathrm{~h}$, $120^{\circ} \mathrm{C}$ for $2 \mathrm{~h}$, and $150^{\circ} \mathrm{C} 2 \mathrm{~h}$, in a stepwise way, as shown in Scheme 1.

2.3. Synthesis of Hyperbranched Poly(MA-EA). Two step reactions were carried out to synthesize hyperbranched poly(MA-EA), in the first step, $1.1 \mathrm{~mol}$ of methylacrylate 
<smiles>C=CC(=O)OC</smiles>

Methylacrylate (MA) $\mathrm{AB}$<smiles>NCCO</smiles>

Ethanolamine (EA) $\mathrm{DC}_{2}$<smiles>COC(=O)CCN(CCO)CCC(=O)OC</smiles>

Intermediate $\mathrm{DA}_{2}$

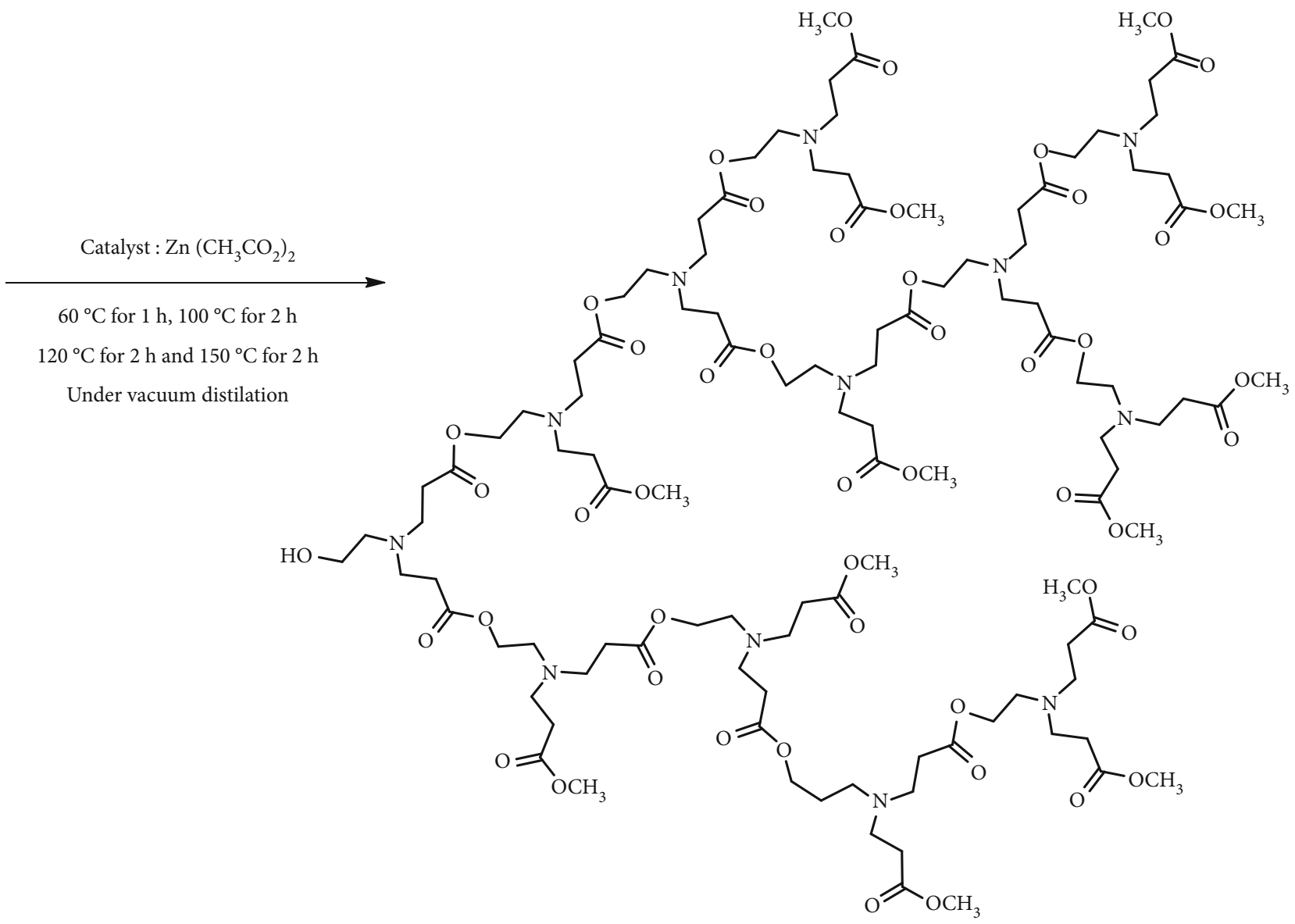

Scheme 2: Synthetic route of hyperbranched poly(MA-EA) (HBP2).

(MA) and $0.5 \mathrm{~mol}$ of ethanolamine (EA) was added into methanol $(100 \mathrm{~mL})$ and stirred for $48 \mathrm{~h}$, and $0.25 \mathrm{~g}$ of $\mathrm{Zn}\left(\mathrm{CH}_{3} \mathrm{CO}_{2}\right)_{2}$ was added to the solution, and then the reaction was carried out stepwise at $60^{\circ} \mathrm{C}$ for $1 \mathrm{~h}, 100^{\circ} \mathrm{C}$ for $2 \mathrm{~h}$, $120^{\circ} \mathrm{C}$ for $2 \mathrm{~h}$, and $150^{\circ} \mathrm{C} 2 \mathrm{~h}$, in a stepwise way, as shown in Scheme 2.

For the preparation of epoxy/HBP thermoset mixtures, $\operatorname{HBP}(0,3,5$, and $10 \mathrm{wt} \%)$ was added to epoxy resin and mixed under vacuum; then, curing agent D-400 (DGEBA/D $-400=1: 0.5 \mathrm{w} / \mathrm{w}$ ) was added to the epoxy resin. Finally, the epoxy mixture was cured in the mold at $125^{\circ} \mathrm{C}$ for $2 \mathrm{~h}$ in an oven.

2.4. Tensile Toughness Calculation. The tensile test was made by gripping the ends of a suitably prepared standardized test piece containing epoxy/HBP blends in a universal testing machine (UTM) and then applied a continually increasing uniaxial load until failure occurs. Afterward, both the load (stress) and the test piece extension (strain) are measured and from this data, and an engineering stress/strain curve is constructed. The tensile toughness of epoxy/HBP blends was measured by calculating the area under the stress-strain curve. The critical values obtained after calculation is the tensile toughness of the tested samples. The tensile toughness equates to a slow absorption of energy by the material.

\section{Characterization}

FT-IR analysis was carried out using a Spectrum GX instrument in a wavelength range of $4000-400 \mathrm{~cm}^{-1}$ to identify the 


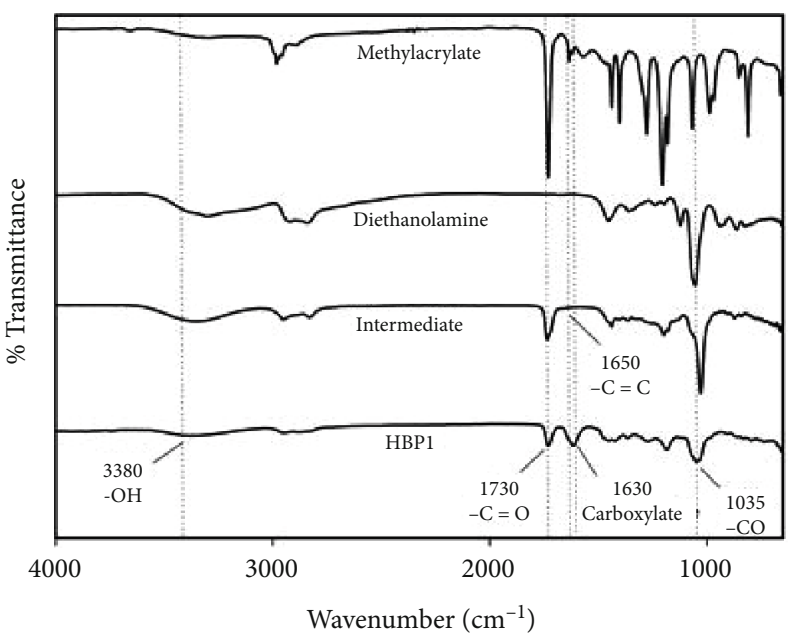

(a)

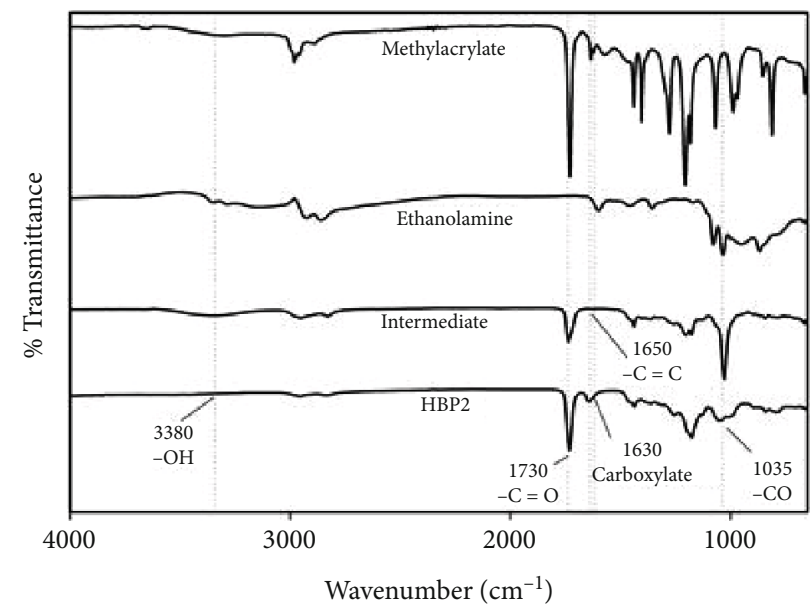

(b)

FIGURE 1: IR spectrum of (a) hyperbranched poly(MA-DEA) (HBP1) and (b) hyperbranched poly(MA-EA) (HBP2).

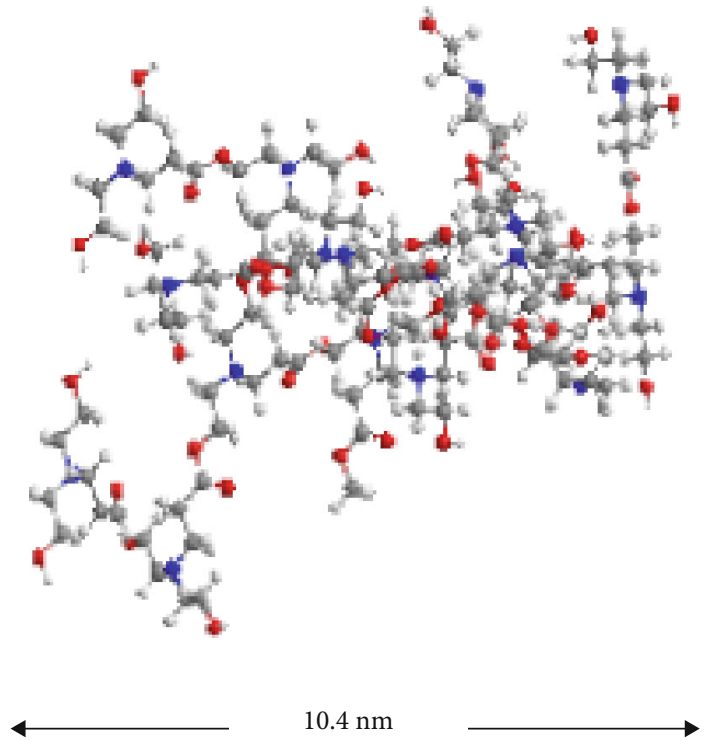

(a)

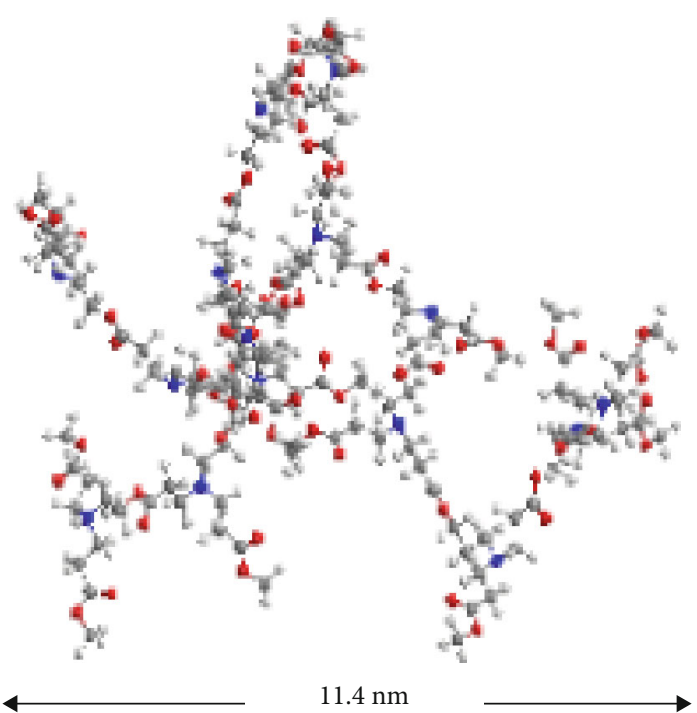

(b)

Figure 2: Expected molecular diameter of (a) HBP1-3.0 K and (b) HBP2-3.1 K.

binding structures. Liquid-state ${ }^{13} \mathrm{C}$ NMR was performed at a frequency of $500 \mathrm{MHz}$ in a FT-NMR Spectrometer (DA208) to confirm the C-bonding structures of the synthesized HBPs. DMA measurements on cured epoxy/HBP blends were performed using Dynamic Mechanical Thermal Analyzer (DMA, Q800) at a fixed frequency of $1 \mathrm{~Hz}$, in the range of -50 to $150^{\circ} \mathrm{C}$ at a heating rate of $5^{\circ} \mathrm{C} / \mathrm{min}$. Dynamic moduli and loss factors were determined.

Tensile properties of epoxy/HBP thermosets were measured at room temperature according to ASTM D638 using a universal tensile tester (Zwick/Roell Z010). The specimens used in the experiment were injection molded dumbbells, the length of the measuring section was $25 \mathrm{~mm}$, the width of the measuring section was $13.2 \mathrm{~mm}$, the thickness of the specimen was $3.54 \mathrm{~mm}$, and the crosshead speed was $50 \mathrm{~mm} / \mathrm{min}$. Impact properties were measured according to
ASTM D4812 using an Izod impact tester (NO258 PL-S Impact Tester, YASUDA SEIKI SEISAKUSHO). The sample used for the measurement was rectangular and the size was $64 \times 12.7 \times 6.4 \mathrm{~mm}$.

\section{Results and Discussion}

The ATR-IR spectrum shows the evidence for the synthesis of intermediates for hydroxy-terminated polyamine esters (HBP1) and methoxycarbonyl-terminated polyamine esters (HBP2). The broadband in the region of $3380 \mathrm{~cm}^{-1}$ is assigned to the $-\mathrm{OH}$ stretching of the ester bonds. The $\mathrm{C}=\mathrm{O}$ stretching and $\mathrm{C}-\mathrm{O}$ stretching were observed at 1730 and $1035 \mathrm{~cm}^{-1}$, respectively. The band emission around $1650 \mathrm{~cm}^{-1}$ indicates the presence of $\mathrm{C}=\mathrm{C}$ bond. The double bond peak in methyl acrylate disappeared as the intermediate was formed during 


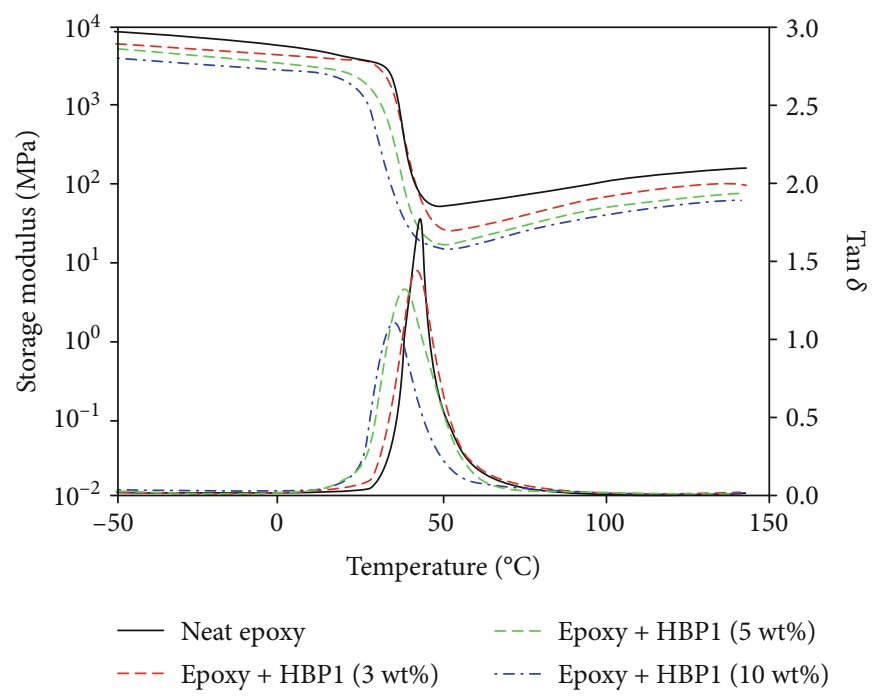

(a)

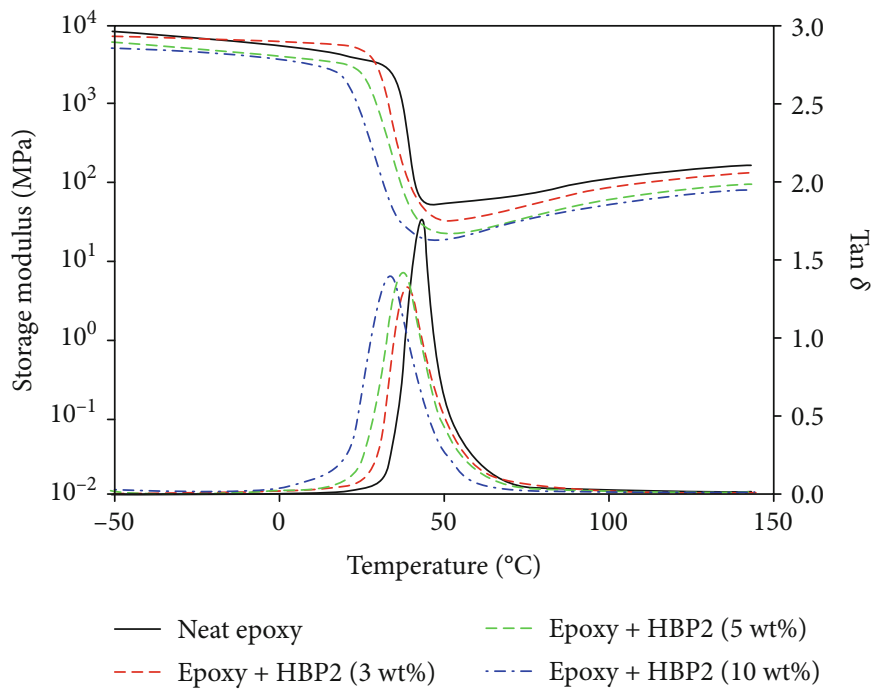

(b)

FIgURE 3: DMA curves of (a) epoxy/HBP1-3.0 K and (b) epoxy/HBP2-3.1 K blends.

the synthesis. HBP1 and HBP2 over the reaction time obtained from ATR-IR spectra are shown in Figures 1(a) and 1(b). For HBP1, a OH stretching peak was found after the polymerization was completed, indicating that a polymer chain with a hydroxyl group was terminated. For $\mathrm{HBP} 2$, the $\mathrm{OH}$ stretching peak, present in the intermediate, disappeared after the polymerization was completed, indicating that a polymer does not have $\mathrm{OH}$ functional group at the polymer chain terminal.

From the ${ }^{13} \mathrm{C}$ NMR-spectrum, the presence of expected atoms was confirmed: $\mathrm{HBP} 1:{ }^{13} \mathrm{C}$ NMR $\left(600 \mathrm{MHz}, \mathrm{CDCl}_{3}\right)$ $\delta$ (ppm): 69.36, 62.61, 59.71, 59.20, 56.76, 52.80, 50.97, $48.69,44.93,33.40,32.49$, and 30.66. HBP2: ${ }^{13} \mathrm{C}$ NMR $\left(600 \mathrm{MHz}, \mathrm{CDCl}_{3}\right) \delta(\mathrm{ppm}): 68.15,62.35,59.56,59.20$, $55.85,52.80,51.63,49.60,44.57,35.88,32.43$, and 30.60 .

The molecular size in diameter was adjusted to about $10 \mathrm{~nm}$ by controlling the molecular weight of HBP1 or HBP2, respectively. The molecular weight ranges from
$1500(1.5 \mathrm{~K})$ to $7000(7.0 \mathrm{~K}) \mathrm{g} / \mathrm{mol}$. The typical estimated molecular size of HBP1 and HBP2 is shown in Figure 2.

After epoxy/HBP1 and epoxy/HBP2 blends were cured, dynamic mechanical thermal analysis (DMA) was performed. All cured blends show one-step change in modulus and a peak in $\tan \delta$, representing no phase separation, as shown in Figure 3. This could be attributed to the miscible or compatible polymer structure, which allows HBP to have sufficient miscibility while avoiding phase separation. For cured neat epoxy (DGEBA), a narrow and distinct $\tan \delta$ peak can be observed around $43.43^{\circ} \mathrm{C}$ which indicates the Tg of cured DGEBA and gradual but steady decreases in Tg were observed for epoxy/HBP1 and epoxy/HBP2 blends. In general, a consistent decrease in $\mathrm{Tg}$ is observed with increasing HBP content, which is evidence of increased residual compatibility of HBPs in cured epoxy, due to the following factors; first, the crosslink density decreases with increasing hyperbranched poly(amine ester) content, and 


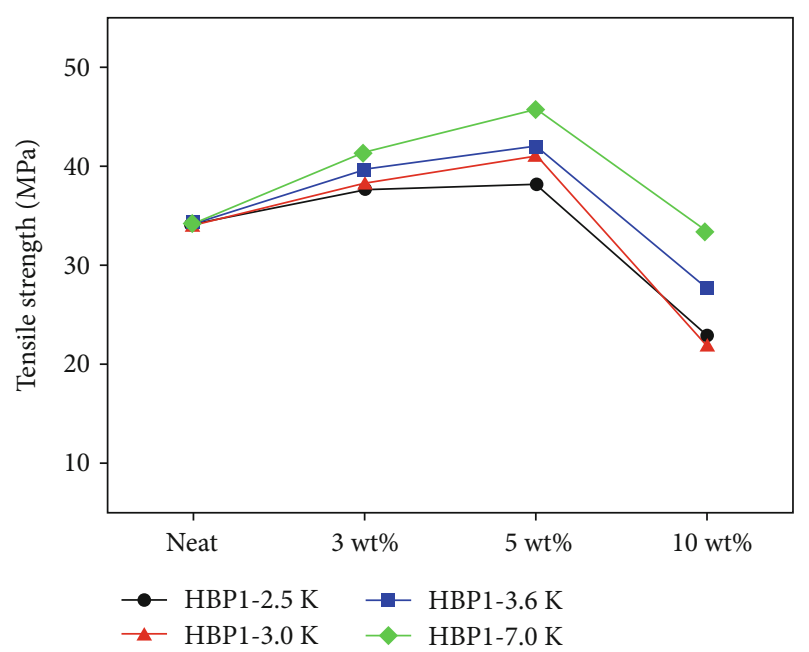

(a)

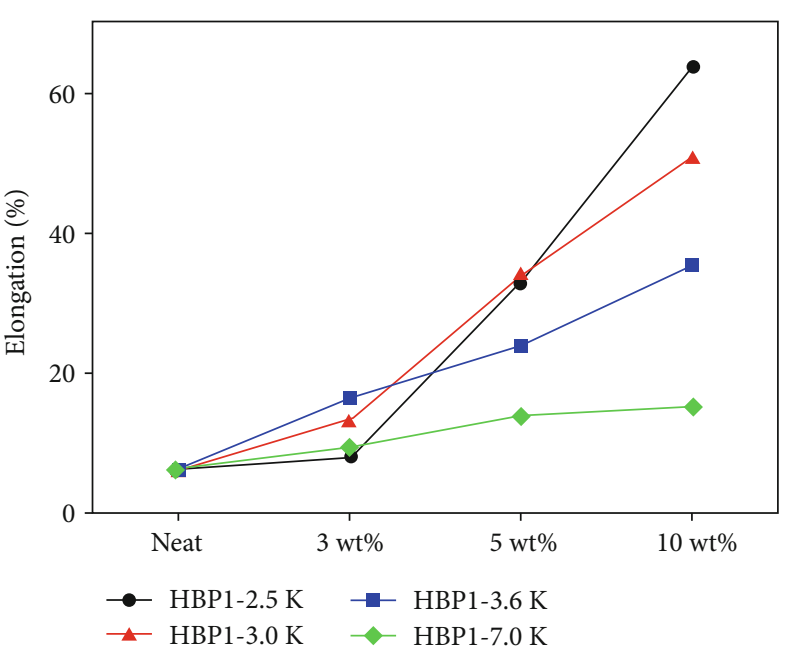

(b)

FIgURE 4: (a) Tensile strength and (b) elongation of epoxy/HBP1 blends with different molecular weights and HBP loadings.

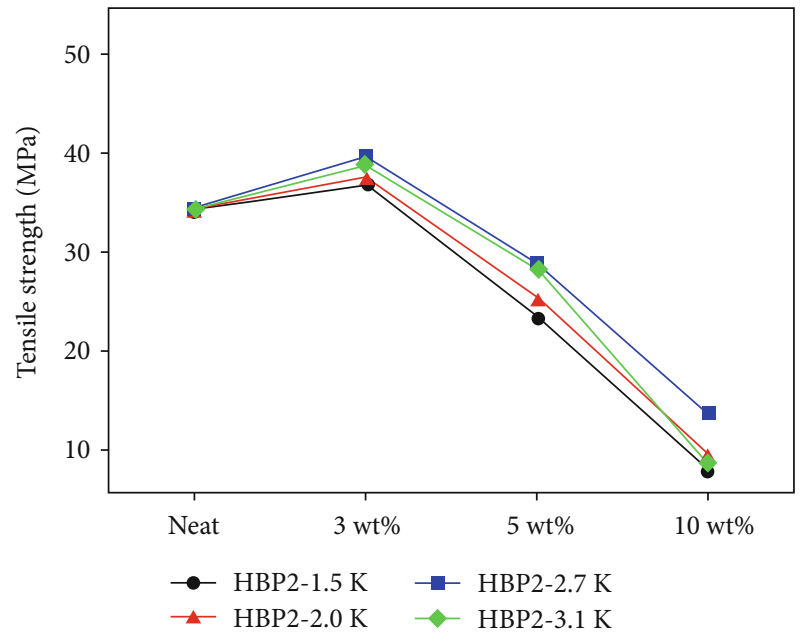

(a)

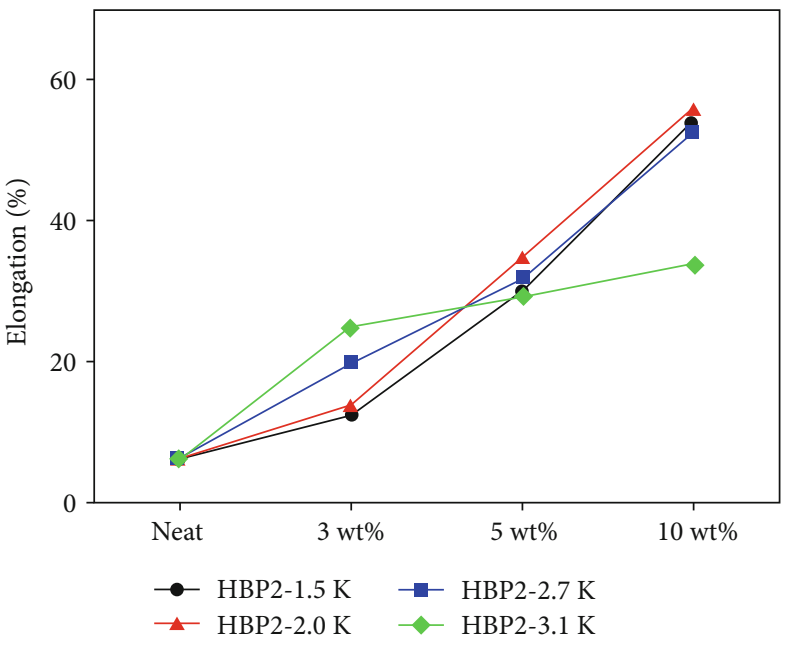

(b)

FIgURE 5: (a) Tensile strength and (b) elongation of epoxy/HBP2 blends with different molecular weights and HBP loadings.

second, the integrated hyperbranched poly(amine esters) reduces the stiffness of the formed network and allows chain movement at lower temperatures. However, the size of HBPs is nanoscale, which could lead to a limitation of the macroscale plasticization of the epoxy matrix. Consequently, narrow changes in Tg were observed for all epoxy/HBP blends.

The tensile strength of cured epoxy/HBP1 and epoxy/ HBP2 blends increased until the HBP content increased to 5 and $3 \mathrm{wt} \%$, respectively, as shown in Figures 4 and 5. Both HBP1 and HBP2 showed a tendency to increase the tensile strength of cured epoxy/HBP blends with increasing molecular weight of HBP. Experimental studies show that the addition of a particular amount of nanoscale soft segment into the rigid epoxy resin changes the internal residual stress and enhances the strength. Moreover, many hydrogen bonds present in HBP1 will provide improvement in the tensile strength of the cured samples. Although, with a high amount of HBPs, the flexible polymer chains may decrease the macroscale stiffness of the epoxy matrix, leading to a weak tensile strength. It is considered that the introduction of free voids presents in the HBP molecule and the free volume between the HBP molecules involved in the cured epoxy network leads to a reduction of the density of the cured epoxy matrix and alters the tensile strength of epoxy networks [27]. Therefore, when the HBP content in the epoxy is relatively low (5 wt\% for HBP1, $3 \mathrm{wt} \%$ for HBP2), a decrease in tensile strength due to negative factors is offset by an increase in positive factors. When the HBP contents increase above $10 \mathrm{wt} \%$ for $\mathrm{HBP} 1$ and $5 \mathrm{wt} \%$ for $\mathrm{HBP} 2$, the negative factors become determinants of the tensile strength. Therefore, the tensile strength of cured epoxy/HBP blends can be decreased by the addition of HBP above a certain 


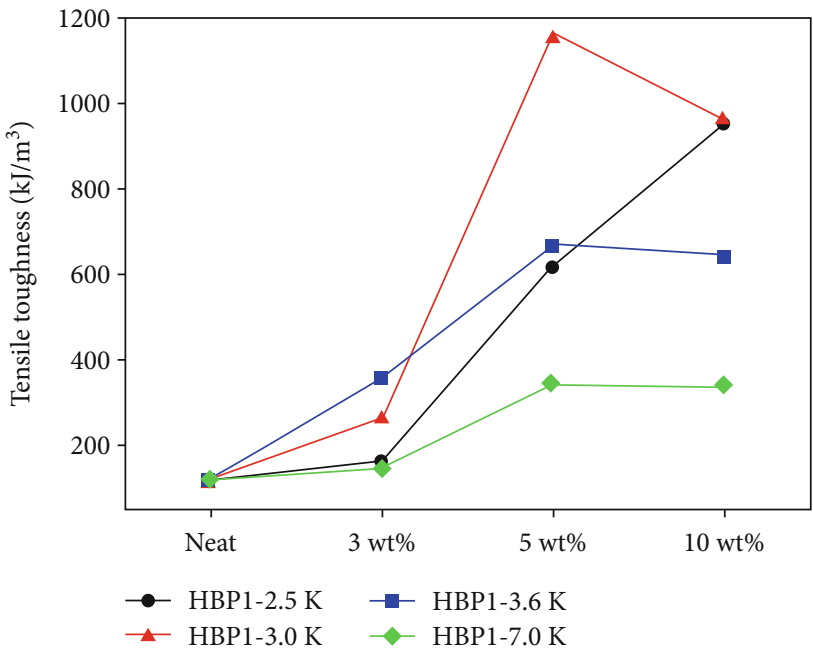

(a)

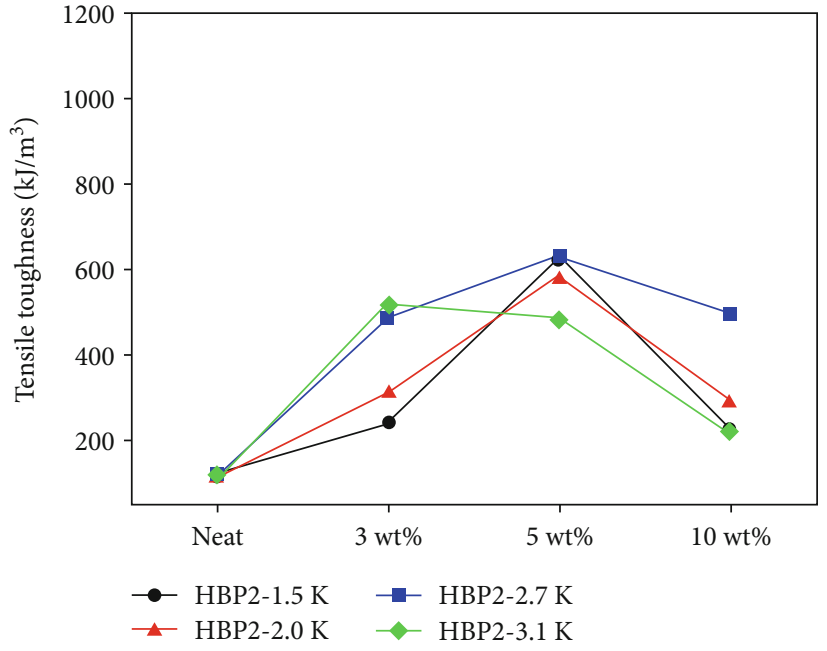

(b)

FIgURE 6: Tensile toughness of (a) epoxy/HBP1 and (b) epoxy/HBP2 blends with different molecular weights and HBP loadings.

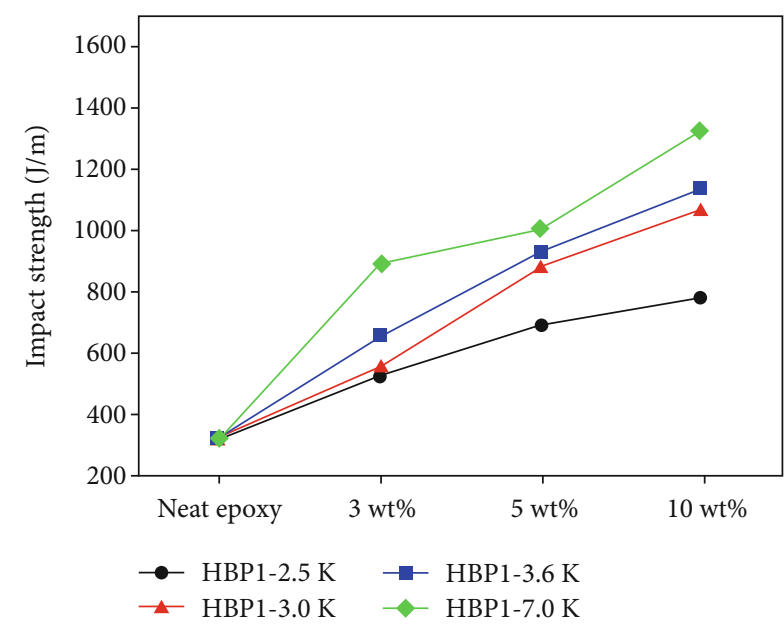

(a)

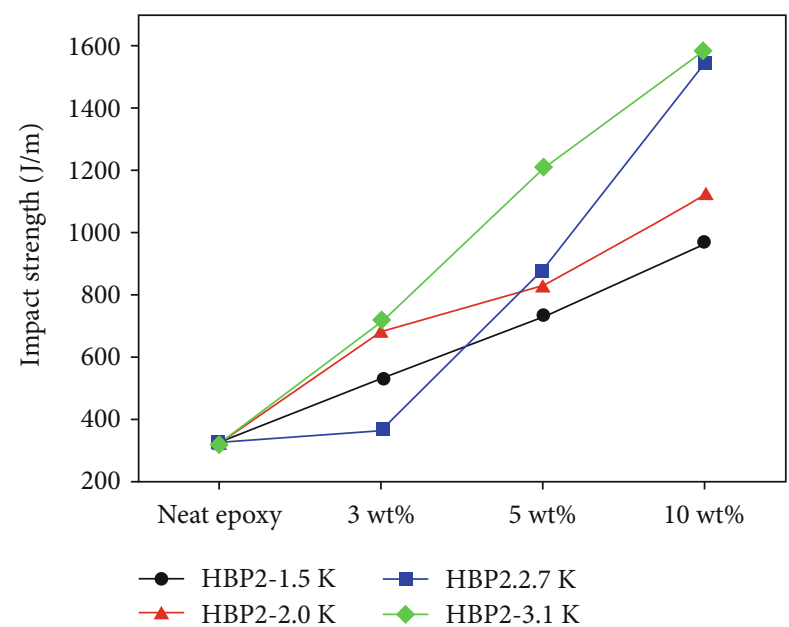

(b)

FIGURE 7: Impact strength of (a) epoxy/HBP1 and (b) epoxy/HBP2 blends with different molecular weights and HBP loadings.

concentration, but the tensile modulus of both epoxy/HBP1 and epoxy/HBP2 blends shows a tendency to decrease with increasing HBP amount. Along with the tensile properties, the incorporation of nanosized flexible HBP into epoxy resin can lead to high elongation properties of epoxy/HBP blends. The elongation properties increase steadily with increasing HBP content. It can be assumed that the ductility of the blends is improved by the presence of free volume and free space in the rigid epoxy matrix by the introduction of spherical HBP which can provide sufficient space, compared to linear flexible polymer, to greatly facilitate the mobility of the polymer chain when the cured epoxy is subjected to tensile forces, which consequently contributes to an increase in elongation with increasing $\mathrm{HBP}$ content.

Tensile toughness can be determined by integrating the area under the strain-stress curve. Generally, strength denotes the amount of force a material can absorb, and toughness indicates the amount of energy a material can absorb before it bursts. Tensile toughness gradually increased as the amount of HBP in the epoxy resin increased, as shown in Figure 6. The highest value for tensile toughness of $1157.82 \mathrm{~kJ} / \mathrm{m}^{3}$ was observed when $3 \mathrm{~K} \mathrm{HBP} 1$ was loaded with $5 \mathrm{wt} \%$ in epoxy resin. For $\mathrm{HBP} 2$, the highest value of $636.02 \mathrm{~kJ} / \mathrm{m}^{3}$ was observed by loading $5 \mathrm{wt} \%$ of $2.7 \mathrm{~K} \mathrm{HBP} 2$. HBP 1 can provide higher tensile toughness performance compared to HBP2 because HBP1 has reactive terminal groups that can strongly resist polymer chain bursting by reactions with epoxy groups.

Figure 7 shows the impact strengths of the cured epoxy/ HBP blends, where the effects of HBP1 and HBP2 contents in the epoxy on the impact resistance are clearly seen. The impact strength of the blends with HBP1 and HBP2 increases stiffly until the loading percentage of both HBP1 and HBP2 in the blends reaches $10 \mathrm{wt} \%$. As the molecular weight of HBP1 and HBP2 increases, the impact resistance also increases, as well. For the blends loaded with $10 \mathrm{wt} \%$ HBP1 and HBP2, the maximum impact strengths were 
1320.73 and $1581.90 \mathrm{~J} / \mathrm{m}$, respectively, showing that the impact resistance was improved by $276 \%$ and $331 \%$, compared to that of cured neat epoxy. When the HBP content is increased to more than $10 \mathrm{wt} \%$, the steric hindrance effect of the HBP content becomes remarkable, and the hydrogen bonding is inhibited, which decreases the impact strength, as reported in the literature [28-32]. In this study, the ester parts in HBP can disperse the impact energy by their segmental motion in polymer chains, which will increase the impact strength. The nanosized free voids and free volumes can also absorb a lot of energy by deforming within a spherical regime and giving free motion in space for the network molecules to move while the impacts are loaded. All mechanical properties of the epoxy/HBP1 and epoxy/HBP2 blends are listed in Table S1 and S2 included in the Supporting Information (SI).

\section{Conclusions}

Nanoscale hyperbranched polymers (HBPs) as flexibilizer of rigid epoxy improve both the toughness and elongation properties of epoxy/HBP blends without affecting the tensile strength of the blends. These HBPs can be used for highperformance structural adhesives especially for bonding hybrid materials that have different CTEs (coefficients of thermal expansion), because epoxy/HBP blends, that have high elongation properties, can adequately absorb CTE differences between two different materials during the thermal curing process of adhesives. In addition, the higher impact strength of epoxy/HBP blends can be achieved by incorporating HBPs into epoxy, which can improve the impact resistance or crash resistance by more than $270 \%$ compared to cured neat epoxy, showing that epoxy/HBP-based structural adhesives can be used for bonding the multimaterials of automotive body structures.

\section{Data Availability}

The data used to support the findings of this study are available from the corresponding author upon request.

\section{Conflicts of Interest}

The authors declare no competing financial interests regarding the publication of this paper.

\section{Acknowledgments}

This research was funded by the Ministry of Trade, Industry, \& Energy (K_G012001112402, the development of CDM (Controlled Delamination Materials) adhesives and dismantling process technology) and the Brain Korea 21 Plus Project.

\section{Supplementary Materials}

Table S1: mechanical properties of epoxy/HBP1 blends. Table S2: mechanical properties of epoxy/HBP2 blends; the information could be accessed in the supplementary material. (Supplementary Materials)

\section{References}

[1] E. N. Gilbert, B. S. Hayes, and J. C. Seferis, "Interlayer toughened unidirectional carbon prepreg systems: effect of preformed particle morphology," Composites: Part A, vol. 34, no. 3, pp. 245-252, 2003.

[2] S. Kang, S. Hong, C. R. Choe, M. Park, S. Rim, and J. Kim, "Preparation and characterization of epoxy composites filled with functionalized nanosilica particles obtained via sol-gel process," Polymer, vol. 42, no. 3, pp. 879-887, 2001.

[3] S. Zulfiqar, I. Fatima, and M. I. Sarwar, "Property profile of nanostructured blends of amine functionalized elastomer and epoxy," Korean Journal of Chemical Engineering, vol. 32, no. 1, pp. 191-198, 2015.

[4] D. Ghim and J. H. Kim, "Effects of composition and layer thickness of a butyl acrylate/acrylic acid copolymer on the adhesion properties," Korean Journal of Chemical Engineering, vol. 33, no. 2, pp. 707-710, 2016.

[5] R. A. Pearson and A. F. Yee, "Influence of particle size and particle size distribution on toughening mechanisms in rubbermodified epoxies," Journal of Materials Science, vol. 26, no. 14, pp. 3828-3844, 1991.

[6] K. T. Gam, M. Miyamoto, R. Nishimura, and H. J. Sue, "Fracture behavior of core-shell rubber-modified clay-epoxy nanocomposites," Polymer Engineering and Science, vol. 43, no. 10, pp. 1635-1645, 2003.

[7] B. J. Derkowski and H.-J. Sue, "Morphology and compressionafter-impact strength relationship in interleaved toughened composites," Polymer Composites, vol. 24, no. 1, pp. 158-170, 2003.

[8] H. Lee and K. Neville, Handbook of Epoxy Resin, McGrawHill, 1967.

[9] C. B. Bucknall, C. M. Gomez, and I. Quintard, "Phase separation from solutions of poly(ether sulfone) in epoxy resins," Polymer, vol. 35, no. 2, pp. 353-359, 1994.

[10] B. S. Kim, T. Chiba, and T. Inoue, "Morphology development via reaction-induced phase separation in epoxy/poly(ether sulfone) blends: morphology control using poly(ether sulfone) with functional end-groups," Polymer, vol. 36, no. 1, pp. 43-47, 1995.

[11] C. Bucknall and I. Partridge, "Phase separation in epoxy resins containing polyethersulphone," Polymer, vol. 24, no. 5, pp. 639-644, 1983.

[12] R. W. Venderbosch, H. E. H. Meijer, and P. J. Lemstra, "Processing of intractable polymers using reactive solvents: 1 . Poly(2,6-dimethyl-1,4-phenylene ether)/epoxy resin," Polymer, vol. 35, no. 20, pp. 4349-4357, 1994.

[13] R. W. Venderbosch, H. E. H. Meijer, and P. J. Lemstra, "Processing of intractable polymers using reactive solvents: 2 . Poly(2,6-dimethyl-1,4-phenylene ether) as a matrix material for high performance composites," Polymer, vol. 36, no. 6, pp. 1167-1178, 1995.

[14] Z. Zhong and Q. Guo, "Miscibility and morphology of thermosetting polymer blends of novolac resin with poly(ethylene oxide)," Polymer, vol. 39, no. 3, pp. 517-523, 1998.

[15] M. Larranaga, E. Serrano, M. D. Martin, A. Tercjack, and G. Kortaberria, "Mechanical properties-morphology relationships in nano-/micro-structured epoxy matrices modified with PEO-PPO-PEO block copolymers," Polymer International, vol. 26, pp. 1392-1403, 2007.

[16] R. M. Hydro and R. A. Pearson, "Epoxies toughened with triblock copolymers," Journal of Polymer Science, vol. 45, pp. 1470-1481, 2007. 
[17] Y. Zheng, S. Li, Z. Weng, and C. Gao, "Hyperbranched polymers: advances from synthesis to applications," Chemical Society Reviews, vol. 44, no. 12, pp. 4091-4130, 2015.

[18] D. H. Zhang, E. B. Liang, T. C. Li et al., "Environment-friendly synthesis and performance of a novel hyperbranched epoxy resin with a silicone skeleton," RSC Advances, vol. 3, no. 9, pp. 3095-3102, 2013.

[19] H. L. Wang, S. P. Xu, and W. F. Shi, "Photopolymerization behaviors of hyperbranched polyphosphonate acrylate and properties of the UV cured film," Progress in Organic Coating, vol. 65 , no. 4, pp. 417-424, 2009.

[20] D. H. Zhang, E. B. Liang, T. C. Li et al., "The effect of molecular weight of hyperbranched epoxy resins with a silicone skeleton on performance," RSC Advances, vol. 3, no. 24, pp. 9522-9529, 2013.

[21] L. J. Luo, Y. Meng, T. Qiu, and X. Y. Li, “An epoxy-ended hyperbranched polymer as a new modifier for toughening and reinforcing in epoxy resin," Applied Polymer Science, vol. 130, no. 2, pp. 1064-1073, 2013.

[22] C. A. May, Epoxy Resins: Chemistry and Technology, Marcel Dekker, 1988.

[23] D. Foix, Y. Yu, A. Serra, X. Ramis, and J. M. Salla, "Study on the chemical modification of epoxy/anhydride thermosets using a hydroxyl terminated hyperbranched polymer," European Polymer Journal, vol. 45, no. 5, pp. 1454-1466, 2009.

[24] F. L. Jin and S. J. Park, "Thermal properties and toughness performance of hyperbranched-polyimide-modified epoxy resins," Journal of Polymer Science Part B: Polymer Physics, vol. 44, pp. 3348-3356, 2006.

[25] H. A. Essawy, H. A. Mohamed, and N. H. Elsayed, "Upgrading the adhesion properties of a fast-curing epoxy using hydrophilic/hydrophobic hyperbranched poly(amidoamine)s," Journal of Applied Polymer Science, vol. 127, no. 6, pp. 45054514, 2013.

[26] S. Li, C. Cui, and H. Hou, "Synthesis and characterization of amino-terminated hyperbranched polymer and its effect on impact resistance of epoxy resin thermosets," Colloid \& Polymer Science, vol. 293, no. 9, pp. 2681-2688, 2015.

[27] Y. Zhao, R. Huang, Z. Wu et al., "Effect of free volume on cryogenic mechanical properties of epoxy resin reinforced by hyperbranched polymers," Materials \& Design, vol. 202, article 109565, 2021.

[28] Y. P. Zheng, Y. Zheng, and R. C. Ning, "Effects of nanoparticles $\mathrm{SiO}_{2}$ on the performance of nanocomposites," Materials Letters, vol. 57, no. 19, pp. 2940-2944, 2003.

[29] G. Levita, S. de Petris, A. Marchetti, and A. Lazzeri, "Crosslink density and fracture toughness of epoxy resins," Journal of Materials Science, vol. 26, no. 9, pp. 2348-2352, 1991.

[30] R. Thomas, D. Yumei, H. Yuelong et al., "Miscibility, morphology, thermal, and mechanical properties of a DGEBA based epoxy resin toughened with a liquid rubber," Polymer, vol. 49, no. 1, pp. 278-294, 2008.

[31] D. H. Zhang and D. M. Jia, "Toughness and strength improvement of diglycidyl ether of bisphenol-A by low viscosity liquid hyperbranched epoxy resin," Journal of Applied Polymer Science, vol. 101, no. 4, pp. 2504-2511, 2006.

[32] Q. Yu, Y. Y. Liang, J. Cheng et al., "Synthesis of a degradable high-performance epoxy-ended hyperbranched polyester," ACS Omega, vol. 2, no. 4, pp. 1350-1359, 2017. 